\title{
Conservadurismo protestante, integrismo y neointegrismo católico latinoamericano y su funcionalidad a los Estados Unidos en el contexto de la Guerra Fría*
}

\author{
Protestant Conservatism, Fundamentalism and Neo-integrism Latin \\ American Catholic and its Functionality to the United States in the \\ Context of the Cold War
}

\begin{abstract}
Resumen
Se analizará la relación entre las redes político-religiosas cristianas conservadoras latinoamericanas y los intereses de Estados Unidos sobre Latinoamérica durante la Guerra Fría. Para ello se analizarán a tres tipos de movimientos religiosos conservadores con una amplia difusión en ese periodo: el conservadurismo protestante, movimiento católico integrista Tradición Familia y Propiedad y el movimiento neointegrista Opus Dei. Se distinguirá el impacto favorable a los intereses estadounidenses que tuvo, el abstencionismo político, la política intraeclesial conservadora, la creación de partidos políticos confesionales y el apoyo a gobiernos de facto a través del ingreso a cargos claves en el estado y el apoyo a grupo paramilitares.
\end{abstract}

Palabras claves: redes político-religiosas, conservadurismo protestante, tradición familia y propiedad, Opus Dei.

\footnotetext{
Abstract

The relationship between conservative Latin American Christian political-religious networks and the interests of the United States over Latin America during the Cold War will be analyzed. To this end, three types of conservative religious movements with a wide diffusion during this period will be analyzed: The

* Este artículo es parte de la investigación desarrollada en el marco del proyecto de investigación "La historiografía de la cultura literaria latinoamericana a través de las redes intelectuales", PICT 2015-0477, financiado por la Agencia Nacional de Promoción Científica y Tecnológica de Argentina (Anpcyt).
} 


\section{Alejandro Paredes}

Protestant conservatism, Tradición Familia y Propiedad fundamentalist Catholic movement and the Opus Dei neo-fundamentalist movement. It will distinguish the favorable impact on American interests that it had, political abstentionism, conservative intra-ecclesial politics, the creation of confessional political parties and support for de facto governments through entering key positions in the state and supporting paramilitary groups.

Keywords: political-religious networks, protestant conservatism, family tradition and property, Opus Dei.

Introducción: algunos aspectos de las redes político-religiosas latinoamericanas durante la Guerra Fría

La red política es un tipo particular de red social, más amplia que los partidos políticos o los movimientos sociales y, de hecho, puede abarcarlos en su interior. La red política es un modo de comprender ciertas prácticas de participación en lo público (Castells, 1997, p.47). Son organizaciones políticas flexibles, con roles no tan fijos, cuyos límites son borrosos (Gonçalves de Freitas y Montero, 2003, p.175). Las redes políticas hacen énfasis en la lucha por la creación y el uso de la información y de la capacidad de generar símbolos. Según Porras (2003) las redes políticas poseen tres características principales: una estructura de vínculos entre actores políticos de las esferas pública y privada; el intercambio de recursos, materiales o inmateriales y percepciones mutuas dependientes con relación a diferentes temas o áreas de la agenda política. El último punto incluye la existencia de un objetivo común entre los miembros de la red política.

La relación entre las redes políticas y los Estados Nacionales es problemática. Los Estados nacionales pueden ser entendidos como una institución arbitral o bien como un espacio nacido de la cristalización de las luchas sociales. Desde la segunda tradición teórica, en cuyo interior coexisten diferentes posturas: epifenomenalistas, instrumentalistas, estructuralistas, hegelianos-marxistas y teorías de la cohesión social, entre otros (Laclau; 1985; Gold, Lo y Wright, 1985) no puede entenderse la existencia de Estados sin redes políticas en su entorno. Pierre Bourdieu plantea la articulación de un Campo de Poder entorno al Estado en cuyo interior distintos actores disputan la obtención del poder estatal (Bourdieu, 1993). Igual que el Campo de Poder, las redes políticas disputan el control del Estado y pueden expandirse o retraerse sobre el territorio nacional e incluso por sobre sus fronteras, dando origen a redes políticas de inmigrantes económicos, de exiliados políticos o de simpatizantes ideológicos. La densidad, duración y grado de expansión de la red política es variable y depende del objetivo de la misma. También pueden superponerse integrándose redes políticas nacionales, regionales y globales, articuladas entre sí.

Hasta mediados del siglo veinte, las organizaciones políticas nacían, principalmente, a partir de una participación fuertemente territorial, como es el caso de los partidos políticos provinciales, nacionales y hasta de los mismos sindicatos. Posteriormente las nuevas tecnologías de la comunicación abrieron la posibilidad al nacimiento de redes políticas vinculadas a partir de objetivos comunes en todo el globo. De todos modos, las redes políticas internacionales no son patrimonio solamente de la sociedad de la información ya que existen ejemplos anteriores como el apoyo internacional a los republicanos en la Guerra Civil Española, a la Revolución Cubana, a 
la redemocratización a las dictaduras militares del Cono Sur en los setenta, entre otras. Todo esto permitieron la creación de lo que Berger y Luckmann (1995) llaman "Comunidades de Sentido" pero transnacionales, que reafirman cosmovisiones y refuerzan identidades grupales en pugna, unas con otras, en una lucha simbólica. Es aquí donde la práctica religiosa reactualiza su eficacia como una herramienta política.

Plantear la existencia de redes político-religiosas implica, como afirman Mallimaci, Donatello y Cucchetti (2006) reconocer "la convivencia de opciones religioso-políticas consagradas en los discursos sociales" (p.424). En América Latina las relaciones entre lo religioso y lo político son muy frecuentes ya que los actores de ambos campos recurren uno al otro para legitimizarse y posicionarse en su propio campo (Mallimaci y Giménez Béliveau, 2007). El vínculo entre religión y política aparece bajo un doble carácter: una relación de competencia y una de complementariedad. Competencia para resguardar la identidad diferenciada entre la religión y la política, y complementariedad, cuando la religión usa a lo político para capitalizarse, y cuando lo político extrae de lo religioso un plus de sentido para la organización social. Para estos autores a pesar de los grados de autonomía de estas dos esferas, la dirigencia política latinoamericana aún sueña con un obispo cercano que les dé su bendición.

La religiosidad es sustento ideológico de una vasta cantidad de organizaciones políticas, como movimientos, partidos, sindicatos y distintas organizaciones de base, y muchas redes político-religiosas establecieron estrategias para lograr el control del accionar estatal en Latinoamérica. Como veremos más adelante, regímenes totalitarios latinoamericanos obtuvieron apoyo de parte del cristianismo conservador (católico y protestante), apelando a su lucha contra el comunismo. Una estrategia del catolicismo integrista, que adquirió gran visibilidad en Argentina, fue la de colocar a sus militantes en diversos puestos de la burocracia estatal con el apoyo de los gobiernos autoritarios de turno. De este modo cientos de ellos se incorporaron a sus filas reivindicando su identidad católica (Mallimaci, 1992). Para estos militantes, el poder institucional de la Iglesia Católica estaba por encima de los poderes civiles, sobre los cuales presionaban para que se adecuen a sus postulados con el fin de recatolizar a la sociedad (Mallimaci, Donatello y Cucchetti, 2006; Olguín, 2010). En el sentido opuesto, también pueden encontrarse redes político-religiosas de disenso como fueron el Movimiento de Sacerdotes para el Tercer Mundo en Argentina, el grupo vinculado a la Vicaría de la Solidaridad en Chile, ISAL en Brasil y otras que van:

[...] desde los grupos guerrilleros en la Argentina hasta la participación de los grupos cristianos de base en el proceso de la Revolución sandinista en Nicaragua durante los años 80 y en el movimiento de los Sin Tierra en Brasil en los años 90; la política de defensa de los derechos humanos de las Iglesias chilena y brasileña durante las dictaduras militares de los años 60 y 70. (Mallimaci y Giménez Béliveau, 2007, p.58)

En este sentido, en América Latina los conflictos intra e intereclesiales provinieron más bien de posturas políticas. A diferencia de otras regiones del globo, hacia la segunda mitad del siglo XX las sociedades modernas latinoamericanas habían logrado evitar guerras religiosas y, en general, permitieron la convivencia de todos los credos en sociedades plurales ${ }^{1}$. Las hostilidades emergieron más bien al interior de cada iglesia entre sectores progresistas y conservadores, y pueden entenderse principalmente como manifestaciones de conflictos entre clases sociales. Esto

\footnotetext{
${ }^{1}$ Aunque no deben olvidarse dos dolorosas excepciones como los dos atentados a instituciones judías en Argentina
} en 1992 y 1994 por parte del terrorismo internacional. 
se agudizó cuando el progresismo cristiano entró en diálogo con el marxismo creando la teología de la liberación (Barón, 2015). En muchas ocasiones las tensiones bajo la apariencia de conflictos religiosos, escondían la lucha por la conservación de privilegios de una minoría, es decir que tenían un marcado carácter de choque de clases. Tal es el caso de la investigación de Jaume Vallverdú (2005) sobre violencia religiosa en Chiapas, México, donde escribe: "Desde principios de los ochenta, más de veinte mil personas, entre seguidores de la teología de la liberación y evangélicos, han sido expulsadas de sus tierras por las autoridades tradicionales vinculadas al poder" (p.67).

Lo mismo puede pensarse de las tensiones que involucraron a movimientos políticos indígenas que rescataron a cultos precolombinos, aunque luego no eran centrales en sus prácticas políticas (Parker Gumucio, 2006). Ejemplo de ello son el Frente Zapatista de Liberación Nacional en México a fines del siglo XX o, ya en el presente siglo, el movimiento nacionalista Aymara en Bolivia (Makaran-Kubis, 2009) o el movimiento mapuche en Chile (Pacheco Rivas, 2012). También se puede incluir a la expansión de las iglesias evangélicas pentecostales entre las comunidades indígenas acompañada por un incremento del respeto a las tradiciones religiosas indígenas tradicionales. Esto dio origen a procesos religiosos novedosos, como el movimiento del Siglo Nuevo, de características mesiánicas y milenaristas que retoma tradiciones indígenas en el área chortí del norte de Honduras (Mena Cabezase y Flores Mejía, 2007).

Otro aspecto es la presencia de líderes religiosos que ingresan en la arena política, incorporándose a la lógica partidaria, en muchos casos tratando de usufructuar su popularidad para capitalizarla en votos. En este sentido, desde mediados del siglo veinte pueden observarse candidatos que a su vez eran líderes religiosos de iglesias evangélicas (Bastian, 1999), Umbandas (Boyer-Araujo, 1993; Daniel, Derrois y de Ávila, 2006) o católica (López Espinola, 2016). A modo de ejemplo, puede mencionarse la investigación de Daniel, Derrois y de Ávila (2006) sobre la candidatura del Pai-de-santo ${ }^{2}$ Toni de Exu Rei candidato del Partido Trabalhista Brasileiro como legislativo estadual en Rio Grande do Sul. En tanto que en la Iglesia Católica fue notorio el caso del presidente de Paraguay Fernando Lugo, obispo emérito de la diócesis de San Pedro. Según Bastian (1999) este proceso de "confesionalización de la política" está ligado a la crisis de legitimidad de los partidos políticos. En este sentido, el ingreso a la arena política de líderes religiosos sería simultáneo al de otros personajes públicos y mediáticos como actores, cantantes o deportistas, en lo que se llamó la Farandulización de la política, durante las democracias neoliberales latinoamericanas de fines de siglo XX (Acevedo, 2016). Sin embargo, mientras que los líderes religiosos dan capital simbólico y, en el caso de las redes político-religiosas, hasta una agenda programática; en la farandulización de la política se asiste a un vacío de contenido de lo político absorbido por la lógica económica (Quevedo, 1999).

Finalmente, el movimiento inverso, es decir el pasaje de la militancia política hacia una religiosa también puede suceder en ciertos contextos especiales. Cuchetti (2007) a partir de un análisis de caso, toma la agrupación peronista Guardia de Hierro para analizar como en algunas trayectorias personales, luego de la muerte del líder político Juan D. Perón, se nota un cambio en la gravitación que va desde la esfera política a otra de la esfera religiosa en el que se suman a un catolicismo de corte integral y militante, que ya se encontraba latente.

${ }^{2}$ Pai-de-santo es el nombre de los sacerdotes varones en las religiones Umbanda, Candomblé y Quimbanda. 


\section{Problema: la materialización de la articulación del cristianismo conservador con la agenda estadounidense para América Latina.}

La presión de los Estados Unidos y el fortalecimiento de la Doctrina de Seguridad Nacional obstaculizaron un giro hacia la izquierda o por lo menos progresista de los países latinoamericanos durante la guerra fría. Al finalizar la segunda guerra mundial, la actitud de Washington hacia América Latina estuvo determinada por tres eventos: la división de las áreas de influencia con la URSS; la derrota de la guerra de Vietnam (1955-1975) y el triunfo de la revolución socialista en Cuba (1959). El primero significó la legitimación del libre accionar de Estados Unidos en el resto del continente americano en tanto que los otros dos fueron vividos como una humillación que provocaron un cambio en las estrategias para el mantenimiento de la hegemonía norteamericana en la región (Paredes, 2004). La salida fue la Doctrina de Seguridad Nacional que para Estados Unidos implicó el apoyo a gobiernos que ejercieran la función de policías en la región. Esta doctrina proponía la existencia del enemigo comunista en el interior de cada país que debía ser eliminado (Duhalde, 1983). Dado que una guerra entre el mundo comunista y el capitalista era poco probable por el alto desarrollo de la carrera armamentista, la tercera guerra mundial se libraría en los países del tercer mundo donde la URSS intentaba conquistarlos a través de la infiltración ideológica en universidades, movimientos religiosos, sindicatos y partidos locales. En este contexto EE.UU. promovió la alianza con los ejércitos latinoamericanos a través de la acción ideológica. Se ofrecieron numerosas instancias de perfeccionamiento para militares de la región que fomentaron la tesis de la infiltración comunista y la de los ejércitos como reguladores de las sociedades y sus democracias.

En este contexto, las prácticas del cristianismo conservador latinoamericano fueron funcional a la lucha antimarxista. En general se afirma que el conservadurismo cristiano latinoamericano de este periodo se manifestó, dentro de la esfera protestante como una abstención a la participación política, en oposición al integrismo y neointegrismo católico que generó principalmente experiencias de militancias político-religiosas. Nuestro propósito es complejizar esta lectura ya que además de la distinción entre el cristianismo protestante conservador y el catolicismo integrista y neointegrista existieron: disputas intraeclesiales (entre grupos conservadores y progresistas), peleas intereclesiales por el posicionamiento de cada iglesia ante los gobiernos de turno, como también, estrategias dentro y fuera de las reglas formales de la democracia para conseguir del poder dominante, concesiones a las reivindicaciones que proponían. Por esta razón nos preguntamos: ¿Cuáles fueron las diferencias en el rol político que asumieron el cristianismo protestante conservador y el catolicismo integrista y neointegrista que eran afines a los intereses de Estados Unidos en la región durante la Guerra Fría? y ¿Cómo se articularon los intereses estadounidenses en América Latina con las prácticas de acción u omisión en el campo político de estos grupos religiosos?

Para analizarlo se han tomado a tres movimientos religiosos cristianos conservadores de gran masividad en ese periodo y se estudiaron a sus implicaciones políticas. El primero es el conservadurismo protestante, el segundo es el movimiento católico integrista Tradición Familia y Propiedad y finalmente, el tercero es el Opus Dei, caracterizado como movimiento neointegrista (Steinleen, 2011) o integrismo no antimoderno (Olguín, 2010) ${ }^{3}$. Con respecto al método, se

${ }^{3}$ Esto no implica desconocer en el complejo mundo del conservadurismo cristiano latinoamericano a otras organizaciones como Legionarios de Cristo, Caballeros de Colón, Caballeros de Malta, Sodálites, Alianza Latinoamericana para la Familia (ALAFA), Fundación Dominó, la Fraternidad Sacerdotal San Pio X, la Unión 
contextualizó y describió a cada red, se determinaron sus consecuencias o prácticas políticas y finalmente se los comparó con los objetivos estadounidenses para América Latina en el contexto de la Guerra Fría.

\section{Resultados}

Lo que veremos a continuación no es una descripción del pensamiento del cristianismo conservador sino más bien del activismo político que realizaron amparadas en sus apreciaciones religiosas.

\section{El conservadurismo protestante latinoamericano y sus prácticas políticas.}

Con respecto al accionar político funcional a los intereses estadounidenses del protestantismo conservador se encuentran dos grandes tendencias: en un primer momento el predominio de la abstención política y el silencio cómplice, posteriormente en el contexto de la redemocratización de la mayoría de los países latinoamericanos se asiste a la creación de partidos políticos confesionales conservadores. Fuera de ambas tendencias está el proceso vivido en Guatemala entre 1982 y 1989, cuando un gobierno de facto fue dirigido por el General Efraín Ríos Montt, quien a su vez era pastor de la Iglesia evangélica del Verbo.

En oposición a sus pares católicos los conservadores protestantes, conscientes de ser religiones minoritarias, se manifestaron principalmente como una no participación en política de sus feligreses hasta entrada la década de 1980. Esto se debió también a la influencia del pietismo, que podríamos sintetizarlo como una teología centrada en las implicaciones personales y espirituales del evangelio, pero que descuida o niega a los aspectos sociopolíticos del cristianismo. El pietismo, o el quietismo con que se lo identifica a veces, se manifiesta como una división entre lo mundano y lo espiritual, en el que se la una prioridad casi absoluta a lo segundo (Weber, 1998, pp.193-208). También implica la espiritualización del evangelio y la promoción del individualismo. Lo primero significa que la pobreza, la alienación, la reconciliación y la salvación se entienden como una relación individual con Dios y rara vez se lo relaciona con el contexto sociohistórico. La espiritualización del Evangelio también puede verse en la idea que contribuir con dinero para aliviar a la desnutrición, la pobreza o los desastres naturales es totalmente aceptable, pero participar en el análisis social y sugerir la sustitución de los actuales sistemas políticos y económicos que conducen a esos problemas es inaceptable. El

Sacerdotal Marcel Lefebvre, entre otras (Ruiz, 2005). Tampoco tomaremos en este artículo las tensiones al interior de la iglesia católica entre los grupos eclesiales conservadores como el sedevacantismo, el lefebvrismo y el antiprogresismo posconciliar radical o conservadurismo integrista. El primero plantea que los papas posteriores a Juan XXIII no fueron electos legítimamente o cayeron en herejía por introducir en la misa elementos litúrgicos protestantes o dialogar con otras religiones en lugar de exigir su conversión. El lefebvrismo es un poco más moderado porque aun cuando denuncia que el Concilio Vaticano II propició prácticas heréticas y la laicización de la iglesia, nunca negó la legitimidad de los sucesores de Juan XXIII. El Lefebvrismo se opone a la aceptación de la libertad religiosa y la separación Iglesia-Estado. Finalmente, el antiprogresismo posconciliar radical o conservadurismo integrista acepta a los papas posteriores a Juan XXIII y al Concilio Vaticano II, aunque lo interpreta en un sentido conservador y en las décadas de 1960 y 1970 se opuso fuertemente a las innovaciones más progresistas de la iglesia (Villegas, 2017). 
individualismo, por otra parte, impide el desarrollo de una ética social cristiana efectiva porque el pecado y la salvación son pensados en términos de necesidades y problemas individuales y no colectivos (Kretzschmar, 1989, p.109).

Según Julio Córdova Villazón (2014) en los sesenta y setenta, en la mayoría de las iglesias protestantes de América Latina predominó una actitud de no confrontación con el poder político y económico. Con discursos religiosos de "obediencia a la autoridad" y de "trabajo responsable", en su gran mayoría, las iglesias evangélicas aceptaron desde la pasividad, como la mejor opción a los regímenes militares de entonces. El evangélico cubano Héctor Méndez, por ejemplo, recordó con tristeza como le sorprendió que en 1976 durante una reunión en Costa Rica de la Unión latinoamericana de Jóvenes Evangélicos (ULAJE), muchos de sus miembros se resistieron a tener momentos de oración por los compañeros ecuménicos que estaban desaparecidos o habían muerto "al servicio del pueblo" (Pereira Ramalho, 1988).

También los líderes de las misiones evangélicas norteamericanas en América Latina tomaron, en general, esta actitud apolítica, aunque eran claramente conservadores. De este modo evitaban hablar de su apoyo a políticas estadounidenses en Latinoamérica que eran polémicas. Esta era la posición de las dos principales asociaciones misioneras, la Asociación Interdenominacional de Misión Extranjera (IFMA) y la Asociación Evangélica de Misiones Extranjeras (EFMA) y también de la Confraternidad Evangélica Internacional (WEF), que era más pequeña. En el centro de la derecha religiosa del movimiento misionero evangélico se encontraban grupos que difundieron su apoyo a los "Contras" en Nicaragua, tales como, Cadena Cristiana de Difusión de Pat Robertson y pequeños grupos carismáticos como Maranatha y Misiones Transmundiales. En el segundo anillo estaban las iglesias que se abstuvieron de manifestar su apoyo a los contras, pero que identificaban estrechamente los intereses norteamericanos con el evangelismo, un ejemplo era Puertas Abiertas con el Hermano Andrés. En el tercer anillo figuraban aquellas que, al igual que las dos primeras, apoyaron la política de Reagan en América Central, pero que eran menos propensas a manifestarlo y se esforzaron por para mantener un frente apolítico. Aquí se pueden nombrar a Cruzada Estudiantil y Profesional para Cristo, Juventud con una Misión y Asambleas de Dios. En el cuarto anillo se encontraba la mayor parte del liderazgo misionero, allí estaban organizaciones igualmente conservadoras pero que demostraron disconformidad con la derecha religiosa y la intervención norteamericana. Algunos ejemplos son los Bautistas del Sur, Misión Centroamericana, Servicio Evangelizador para América Latina (SEPAL) y la Cruzada Luis Palau. Finalmente, en el quinto anillo estaban aquellos grupos con mayor oposición a la derecha religiosa, como las organizaciones humanitarias World Vision y World Relief, Misión Latinoamericana y las misiones menonitas (Stoll, 1990). 


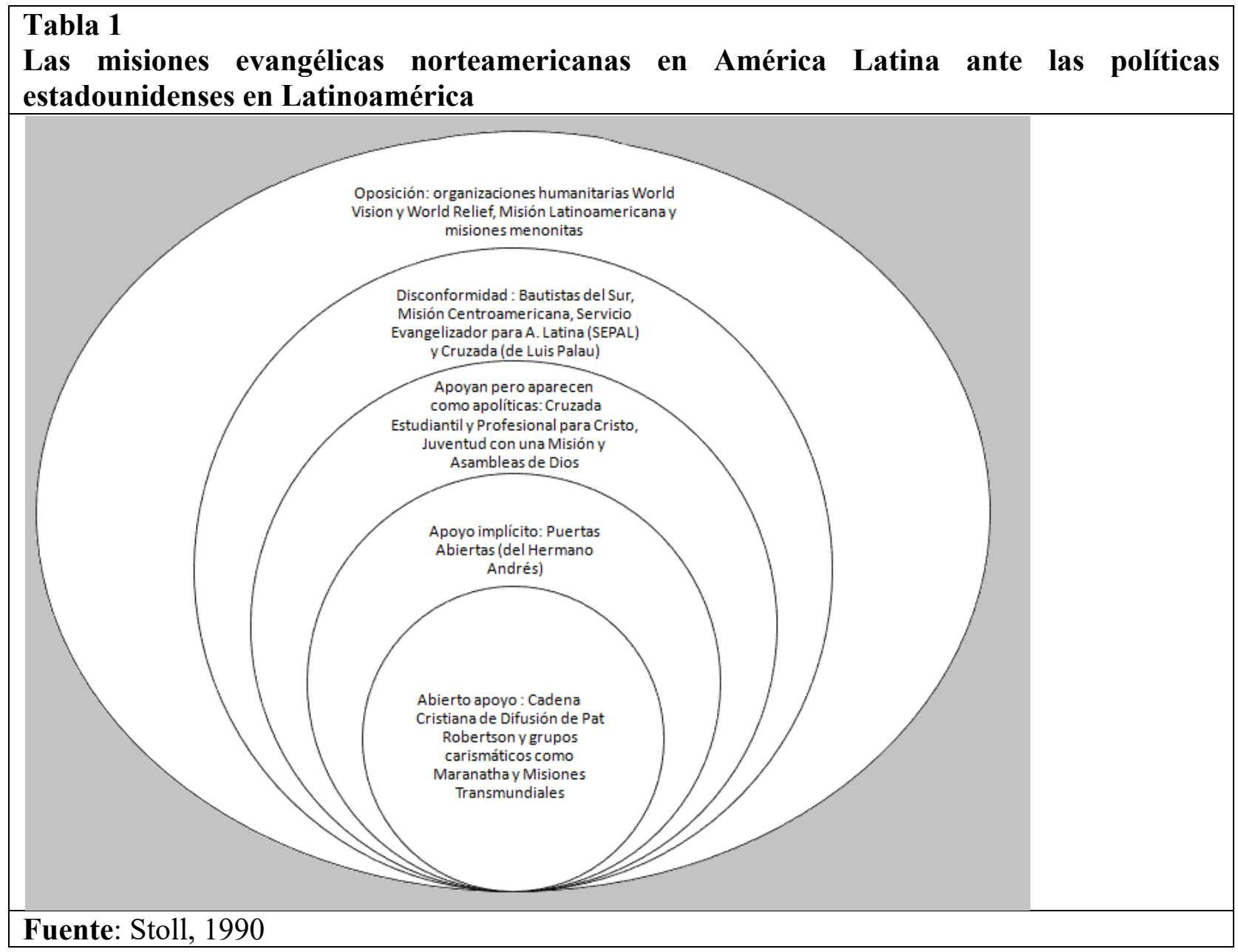

Si bien existieron excepciones a esta huida de la participación política por parte de los evangélicos conservadores, como por ejemplo el abierto apoyo al régimen del General A. Pinochet por parte del Consejo de Pastores de Chile (Mansilla y Orellana, 2015). Sin duda, una gran excepción fue el gobierno de facto del General Efraín Ríos Montt, quien articuló una derecha político-religiosa y presidió Guatemala entre 1982 y 1983 con el activo apoyo de líderes evangélicos conservadores de los Estados Unidos (Stoll, 1993; Piedra, 1999). Ríos Montt era pastor de la Iglesia evangélica del Verbo, nacida en los Estados Unidos y apeló a justificaciones teológicas de su accionar en sus mensajes oficiales (Chacón, 2015). El saldo producido por el ejército y la organización paramilitar PAC (Patrullas de Autodefensa Civil) durante su gobierno fueron de 15.000 asesinatos más de 1.000 desapariciones forzadas y 15 fusilamientos, producto de juicios verdaderamente anómalos. Como consecuencia, más de un millón de personas se desplazaron y 90.000 huyeron a países vecinos (Figueroa-Ibarra, 1990). El gobierno de Ríos Montt, efectuó un genocidio de la etnia Ixil, de ascendencia Maya, por su supuesto apoyo a fuerzas guerrilleras contrarias al gobierno. Esto se realizó por medio de matanzas y desplazamientos masivos, ejecuciones, desapariciones, violación sistemática de mujeres y niñas, 
tortura, traslado de niños, privación de suministros básicos, bombardeos y destrucción de la propiedad con un saldo de más de 29.000 ixiles desplazados de sus hogares y 1.771 personas asesinadas en once de las 626 masacres documentadas, lo que conllevó a la destrucción significativa del grupo étnico (Federación Internacional de Derechos Humanos, 2013). En 2013, el general Ríos Montt fue condenado a 80 años de prisión por genocidio por un tribunal en Guatemala encabezado por la jueza Yasmín Barrios, pero fuerzas conservadoras opuestas al juicio lograron a través la Corte de Constitucionalidad anular la condena días después bajo tecnicismos jurídicos (Flores, 2017).

Pero finalmente fue durante la transición democrática en las últimas décadas del siglo veinte, cuando muchos grupos evangélicos conservadores crearon partidos políticos religiosos. Bastian (1999) menciona la conformación de al menos 26 partidos en Argentina, Bolivia, Brasil, Colombia, Costa Rica, Chile, El Salvador, Guatemala, México, Guatemala, Perú y Venezuela.

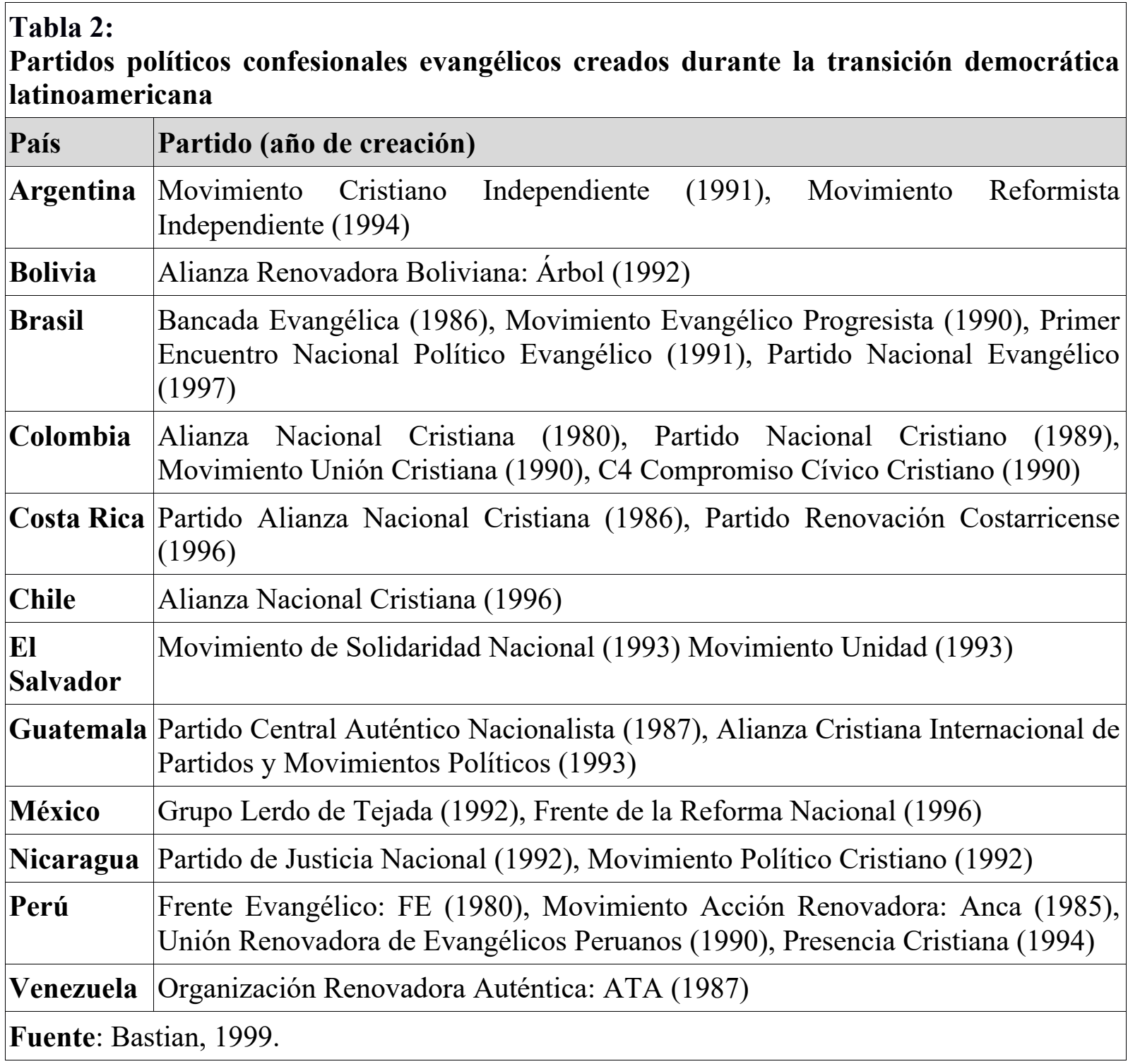


Estos partidos marcaron la presencia en Latinoamérica de actores políticos confesionales, es decir de militantes políticos que ocupan cargos electivos manifestando su identidad religiosa. Sin embargo, como afirman Isaac Caro y Evguenia Fediakova (2000), estos partidos difícilmente conducirían a teocracias ya que surgieron como manifestaciones de la diversidad religiosa, política y cultural de América Latina en el marco de sociedades pluralistas y democráticas.

Paralelamente varias de las iglesias conservadoras evangélicas se unieron bajo la Confraternidad Evangélica Latina, también llamada CONELA, en gran parte como reacción del predomino que el progresismo evangélico había adquirido en el Consejo Latinoamericano de Iglesias (CLAI). En abril de 1982 CONELA se conformó oficialmente en la reunión de Panamá, con la participación de pastores, líderes nacionales, y representantes de 84 denominaciones, de alianzas evangélicas y de organizaciones misioneras. Ya en el siglo XXI, CONELA se fusionó con la Conferencia Nacional de Líderes Hispanos Cristianos NHCLC y mudó su accionar. Ahora la NHCL/CONELA es una red de pastores conservadores en América Latina que buscan participar activamente en la política según sus principios doctrinarios, financiando organizaciones provida y generando lobbies en el poder judicial, entre políticos, medios de comunicación y también entre representantes de la ONU y la OEA (Amat y León, 2015).

\section{Tradición, Familia y Propiedad (TFP) y sus vínculos con grupos paramilitares}

El integrismo católico se enfrentaba a la modernidad en su búsqueda por la restauración de la sociedad cristiana de la Edad Media. Se oponía a la existencia de un Estado Nacional laico ya que afirmaban que la doctrina católica es perfecta y autosuficiente, por lo que desconfiaban de los ideales de la laicidad democrática, de diálogo con el mundo o de convivencia interreligiosa. Desde esta concepción teocrática, la Iglesia Católica Apostólica Romana posee la verdad absoluta, ya que su poder proviene de Dios, por lo tanto, ninguna institución, ya sea estatal o de la sociedad civil, puede colocarse por encima de ella (Olguín, 2010).

El integrismo católico, ya presente en el Concilio de Trento y la contrarreforma, al igual que la romanización y las medidas del Papa Pío XI influyeron en las agrupaciones conservadoras católicas generando experiencias de militancias político-religiosas (Cifuentes, 2007). Para analizarlas, en este artículo tomaremos a Tradición, Familia y Propiedad (TFP). Su fundador fue el brasileño Plinio Correa de Oliveira (1908-1995). Descendiente de una familia noble de la corte del último emperador brasileño ${ }^{4}$, fue miembro de la Liga Eleitoral Católica LEC $C^{5}$, encargado del boletín católico "O Legionário" y Presidente de la Acción Católica de São Paulo (Ruiz, 2005). Desde allí combatió al nazismo, al comunismo y a lo que él consideraba los desvíos del progresismo. En la década de 1950 fue uno de los creadores del periódico mensual "Catolicismo" en torno al cual nacerá Tradición, Familia y Propiedad.

\footnotetext{
${ }^{4}$ De hecho, Plinio Corrêa de Oliveira estuvo involucrado personalmente en la educación de los príncipes Luiz y Bertrand de Orléans e Bragança quienes pretenden el retorno a la monarquía en Brasil ya que ellos son los herederos de la Casa Imperial de Brasil. Posteriormente se unieron a Tradición, Familia y Propiedad.

${ }^{5}$ El programa del LEC incluía los siguientes puntos mínimos: Promulgación de la Constitución brasileña en nombre de Dios; reconocimiento constitucional de la indisolubilidad del matrimonio y de la validez civil del casamiento religioso; la adopción de la instrucción religiosa obligatoria en las escuelas públicas de nivel primario y secundario; y la concesión de la asistencia religiosa oficial a las fuerzas armadas, las prisiones y a los hospitales (Kornis, 2009)
} 
El TFP es un movimiento católico conservador, autodefinido como contrarrevolucionario preocupado por la ortodoxia de la fe, la infiltración del marxismo en la iglesia y en las sociedades occidentales y la liberación de la mujer. El TFP nació en Brasil, pero alcanzó amplia difusión en toda América Latina conformando agrupaciones de este movimiento en 26 países de cinco continentes. En América Latina el TFP ha tomado distintos nombres y ha creado distintas entidades algunas de ellas son: Jóvenes Bolivianos pro Civilización Cristiana; Fundación Argentina del Mañana (Argentina); Asociación de Fundadores (Brasil); Centro Cultural Cruzada (Colombia); Sociedad Colombiana Tradición y Acción; Sociedad Colombiana de Defensa de la Tradición, Familia y Propiedad; Acción Familia por un Chile auténtico, cristiano y fuerte; Tradición y Acción por un Uruguay Auténtico, Cristiano y Fuerte; Lepanto (Uruguay); Tradición y Acción por un Perú Mayor.

Con una práctica radicalmente anticomunista, algunas de las actividades realizadas en el periodo de la Guerra Fría (recordemos que el TFP es una organización aún vigente) fueron:

En 1961, Plinio Correa de Oliveira publicó varias ediciones del libro "Reforma Agraria, Cuestión de Conciencia", escrito junto a Antonio de Castro Mayer, Obispo de Campos; Geraldo de Proença Sigaud, Obispo de Jacarezinho y el economista Luis Mendonça de Freitas. El libro tuvo numerosas ediciones y la prensa de los principales diarios brasileños (De Mattei, 1998). Según su discípulo, Luis Alberto Chávez Hartley ${ }^{6}$ (2011) este libro preparó el clima en la opinión pública brasileña que permitió el derrocamiento de João Goulart en 1964.

En 1968 el TFP reunió 2,2 millones de firma pidiendo al Papa Paulo VI que prohíba la acción de religiosos y laicos cristianos cercanos al marxismo.

A principios de la década de 1970, luego del triunfo del Socialista Salvador Allende en Chile, algunos de miembros del TFP chilenos emigraron a Argentina y trabajaron coordinadamente con el TFP argentino. El TFP chileno había sido fundado en 1967 por estudiantes de la Pontificia Universidad Católica de Chile, que habían creado la revista Fiducia en 1962 (Gomes, 2016), en Argentina recibió el apoyo de su homónimo argentino y hasta 1973 el abierto apoyo del Arzobispo de Mendoza Alfonso M. Buteler. Ambos movimientos se transformaron en fuertes militantes anticomunistas (Ruderer, 2012). En este periodo su principal tarea fue la de "esclarecer la opinión [pública], estimando esto una condición indispensable para la liberación de Chile" (Fiducia, 1974, contratapa). Para esto se realizaron distintas actividades concientizadoras como manifiestos, publicaciones de artículos y organizó actos religiosos. Entre septiembre y octubre de 1970, el TFP en Argentina promovió una campaña en la que repartió en todo el país 250.000 ejemplares del artículo "Toda la verdad sobre las elecciones en Chile" escrito por el doctor Plinio Correa de Oliveira, en la revista chilena Fiducia. También promovió cadenas de rezo del rosario en Mendoza y en Buenos Aires con la intención que Chile no cayera en el comunismo. Otras actividades durante 1970 del TFP fueron una caravana que recorrió 50 ciudades de diferentes provincias difundiendo una revista con artículos del doctor Correa que analizaban la situación chilena y el envío de una carta a Paulo VI pidiendo que actuase ante el crecimiento del comunismo en el país trasandino. También realizaron tareas similares los grupos de TFP en Brasil, Uruguay, Venezuela, Colombia y Ecuador. El 8 de agosto de 1971, el TFP en Argentina publicó en los diarios La Nación, La Prensa y la publicación católica El Esquiu, una carta al General Lanusse pidiéndole que no permitiese la entrada de Allende en la Argentina. La revista "Tradición, Familia y Propiedad" lanzó constantes críticas al gobierno del presidente chileno una de ellas fue un manifiesto del "TFP chileno en el exilio", llamado "Ni armas, ni

${ }^{6}$ Luis Alberto Chávez Hartley es el secretario de Tradición y Acción por un Perú mayor. 
barbas, sino trampas: La vía chilena". Se hicieron 35.000 ejemplares de este documento que se repartieron en varios países de Sudamérica (Fiducia, 1974, p.56). Otro artículo de igual tenor fue "La autodemolición de la iglesia, factor de la demolición de Chile" que fue publicada también en el diario La Nación de Buenos Aires (TFP, 1973).

El TFP tendió a vincularse con la jerarquía católica que le era afín. Las cadenas del rezo del Rosario que propuso el TFP para evitar que Chile cayese en el comunismo contaron con la presencia del Monseñor Alfonso María Buteler, arzobispo de la Mendoza. Buteler había sido nombrado obispo por el Papa Pío XII el 11 de octubre de 1940 y en abril de 1961 fue promovido a arzobispo ${ }^{7}$. Como fiel representante del ala más reaccionaria del catolicismo, en 1965 Buteler no dudó en cerrar el Seminario de Lunlunta y expulsar a los 27 sacerdotes jóvenes que lo habían tomado reclamando el inicio de la apertura eclesial propuesta por el Concilio Vaticano II (MDZ, 25/12/2009). En otra ocasión el arzobispo escribió una carta felicitando al militante de TFP, Dr. Fabio Xavier da Silveira, por su libro "Frei, el Kerensky chileno" (también reproducido por las revistas del movimiento TFP "Catolicismo", junio-julio 1967 y "Cruzadas", agosto-septiembre 1967). Según Silveira, Freire había preparado el camino para la ascensión de la minoría marxista al poder en Chile, como lo había hecho Alejandro Kerensky con la ascensión de Lenin en Rusia. La Carta de Buteler decía lo siguiente:

Todo lo que el autor ha recopilado con habilidad de buen observador lo tengo yo comprobado por la vecindad en que me encuentro. Lo que es muy de lamentar es que ese Kerensky haya encontrado un aliado allí donde debió encontrar la mayor resistencia. (Comisión de Estudios de las TFPs, 1990)

En 1981, realizaron una campaña en contra del presidente francés François Mitterrand, acusándolo de comunista. Publicaron el documento "El socialismo autogestionario frente al comunismo: ¿barrera, o cabeza de puente?”, en 187 periódicos y revistas de 54 países, en 14 idiomas, con un total de 34.767.900 ejemplares. Finalmente, en 1990, comenzaron otra campaña esta vez a favor de la independencia de Lituania un país de población en su mayoría católica que aún pertenecía a la URSS para ellos se reunió más de cinco millones de firmas en veinte países.

Un libro publicado por Plínio Correa de Oliveira pocos años antes de su muerte resumió el pensamiento de este movimiento religioso. Se llama "Nobleza y élites tradicionales análogas en las alocuciones de Pío XII al Patriciado y a la Nobleza romana". En él señala que, "apoyándose en la doctrina expuesta por Pío XII, [...] el único medio de evitar que la sociedad actual se despeñe en el caos es que las élites auténticas reasuman, consciente y resueltamente, su misión de servidoras del bien común" (Chávez Hartley, 2011).

Otro aspecto importante a destacar del TFP es que hay pruebas de miembros suyos que han militado en grupos violentos de extrema derecha en México, Argentina, Chile y Colombia. Mientras que se han denunciado campos de entrenamientos militares a los que asistían militantes del TFP en Brasil, Paraguay, la frontera argentino-chilena y Colombia.

En la década de 1960, el TFP de México se vinculó con un violento grupo anticomunista llamado MURO, Movimiento Universitario de Renovadora Orientación. Su publicación se llamaba "Puño" y sus acciones fueron golpizas, enfrentamientos con armas de fuego en diferentes

\footnotetext{
7 Ver su biografía en la página oficial de la diócesis de Mendoza. http://aica.org/aica/igl_arg/circuns_ecles/diocesis/mendoza.htm
} 
escuelas, robos de expedientes de estudiantes universitarios, sabotaje de actos públicos, amenazas y protestas públicas (Ruiz, 2005).

En los setenta, cuando Salvador Allende obtuvo la presidencia de Chile, el TFP se vinculó con Patria y Libertad, que era una organización paramilitar chilena de tendencia neofascista que recibió dinero de la CIA (Gomes, 2016). El periodista Antonio Restrepo en el diario "Nación" de Colombia denunció que miembros del TFP viajaron a Brasil para prepararse en campos especiales, en karate-dó, paracaidismo y tácticas de lucha en las calles, para luego integrarse al grupo Patria y Libertad en Chile (Restrepo, 1982). Otro campo similar funcionó en Paraguay (Gomes, 2016) y en Mendoza, principal ciudad argentina más cercana a Santiago de Chile (El Siglo, 8/5/73, p.9). El dos de mayo de 1973 los chilenos Juan Sessa y Roberto Thieme, fueron arrestados luego de aterrizar clandestinamente en una estancia cercana a una propiedad de un chileno miembro del PyL (Bustelo, 2001). Roberto Thieme era el Secretario General de Patria y Libertad y Juan Sessa, el encargado de Hombres y Operaciones de esa agrupación. En el avión se encontraron armas y folletos políticos. También había cerca de cinco mil dólares, una lista de contribuyentes de Argentina, Brasil y Paraguay, y una carta dirigida a Pablo Rodríguez Grez de Arturo Marshall, un antiallendista asilado en Bolivia, en la que escribía que enviaba quince mil dólares,

con el objeto de cubrir gastos que exige la realización del plan establecido previamente" continuaba la esquela: "En las próximas elecciones se jugará el destino de Chile. En ellas debe triunfar el destino de la verdadera democracia. Por esta razón constituye para nosotros una gran satisfacción prestarle ayuda en la medida de nuestros recursos. (El Siglo, 8/5/73, p.9)

Finalizaba diciendo que enviaría unos bultos para que sean utilizados en el momento conveniente.

John Oleafer, tercer hombre del PyL luego de Rodríguez y Thieme, había estado en Mendoza una semana antes del escándalo del aterrizaje clandestino (El Siglo, 8/5/73, p.9). Alberto Velásquez Buitano, cónsul de Chile en Mendoza, afirmó que esto tenía vinculación con fuertes capitalistas chilenos en Mendoza y con el contrabando de armas. También agregó que "los chilenos en Mendoza quieren convertir a esa ciudad en escenario de actividades conspirativas" (Claves, 1973, p.43).

Walter Roberto Thieme había fingido su muerte en un accidente de aviación en el sur de Chile, el 23 de febrero de 1973. Días antes en una conferencia de prensa había afirmado que el objetivo de Patria y Libertad era echar a Allende. También agregó que para ello tendrán que actuar las Fuerzas Armadas Chilenas y “[...] como estas no podrán controlar solas la situación, necesitarán de una fuerza civil que las apoye y esa fuerza civil somos nosotros y nos estamos preparando para ello" (El Siglo, 7/5/73, p.3).

Según el diario El Siglo, Thieme era el encargado del entrenamiento de fuerzas de choque para un enfrentamiento civil en los campos de entrenamiento para la formación de grupos paramilitares que se encontraban en la cordillera mendocina (El Siglo, 7/5/73, p.3). Sessa y Thieme revelaron su participación en una conspiración para derrocar a Salvador Allende (El siglo, 9/5/73, p.3 $)^{8}$. Posteriormente, cuando la DINA fue creada por el General Pinochet en 1974,

${ }^{8}$ En ese mismo periodo nació en Mendoza una organización armada cristiano-conservadora aunque no hay pruebas de hayan miembros del TFP en ella. Se llamaba Comando Moralizador Pío XII, estuvo vinculada a la Triple A y 
muchos de los militantes de Patria y Libertad formaron parte de los 2.000 civiles que, empleados como técnicos y profesionales (principalmente médicos), se encargaron de lo que se llamó el "trabajo sucio" de la DINA (secuestros, interrogatorios, torturas) y fueron parte de grupos civiles armados como Comando Carevic, Comando de Vengadores de Mártires (COVEMA), El escuadrón de la Muerte, el Grupo Flama, Comando Roger Vergara, Comando Amigos de Cristo en Chile y Grupo de Hombres Araña, la araña negra era el símbolo de Patria y Libertad (Orellana, 1981, pp.8, 20).

Otros sucesos violentos en los que participaron miembros del TFP sucedieron en Venezuela y en Colombia. El 13 de noviembre de 1984 la policía frustró un proyecto del TFP para asesinar a Juan Pablo II durante su viaje a Venezuela. En 1988 se produjo un asesinato de 21 campesinos aparentemente socialistas de dos fincas bananeras de Urabá, en Colombia. El mismo fue realizado bajo el asesoramiento de un sicario israelí llamado Yair Klein y con la participación de un miembro de Tradición Familia y Propiedad, el Mayor Isauro Hernández Hernández de la XX Brigada colombiana. Klein salió de Colombia hacia Honduras, para dar instrucción a los contras nicaragüenses, patrocinados por los Estados Unidos (Ruiz, 2005).

\section{La doble estrategia política del entorno del Opus Dei}

Esta orden fue fundada en 1928 en España por José Escrivá de Balaguer y gozó del apoyo de Francisco Franco.

El Opus Dei se sitúa dentro del catolicismo integrista [...] y de la corriente nacionalcatólica pero con la diferencia que logró compatibilizar el espíritu anti-moderno del catolicismo integrista con el desarrollo del capitalismo en España, aunque siempre dentro de los presupuestos ideológicos del franquismo. (Olguín, 2010, p.110)

Es por esto que Cedric Steinleen (2011) lo define como a un neointegrismo, debido a la capacidad del Opus Dei de adaptarse a la modernidad en lo económico, pero con un marcado sello integrista e intransigente en lo moral. Opus Dei desembarcó en América Latina a mediados del siglo XX, en 1949 llegó a México, luego a Chile y Argentina (1950), Colombia y Venezuela (1951), Perú y Guatemala (1953), Ecuador (1954), Uruguay (1956), Brasil (1957), El Salvador (1958), Costa Rica (1959), Paraguay (1962), Puerto Rico (1969), Bolivia (1978), Honduras (1980), Trinidad y Tobago (1982), República Dominicana (1988), Nicaragua (1992) y Panamá (1996). México, Argentina y Colombia están entre siete los países con más miembros en el mundo (Amado, 2014).

Puede pensarse en dos estrategias políticas del Opus Dei. La primera ha sido influir en los gobiernos de cada país por medio de la infiltración del movimiento entre sus dirigentes (Ruiz, 2005). La segunda fue la de posicionarse en la jerarquía católica con el apoyo del Papa Juan Pablo II (con quien ya estaba vinculado desde la década de 1970 cuando era obispo de Cracovia),

actuó en Mendoza entre 1974 y 1976 (Rodríguez Agüero, 2009). El Comando Pío XII además de ser cercano a sectores institucionales de la iglesia católica se ligó con grupos policiales y las fuerzas armadas. Ejerció la violencia paramilitar matando a prostitutas, homosexuales y artistas, y realizando atentados en cabarets, albergues transitorios y discotecas. De este modo procuró ejercer una función disciplinadora hacia aquellos que según ellos buscaban la "subversión de valores". 
a través de la política de nombramientos de obispos, arzobispos y cardenales, y de la persecución de los teólogos de la liberación y de los jesuitas más aperturistas (Tamayo Acosta, 2005).

Con respecto a la primera estrategia, esta congregación religiosa, formada por sacerdotes, numerarios, supernumerarios, agregados y cooperadores, se ha preocupado por relacionarse con las élites nacionales. Con este fin ha creado numerosas instituciones educativas para la clase alta, entre las que sobresalen la Universidad Panamericana de México, la Universidad de la Sabana de Colombia, la Universidad de Piura de Perú, la Universidad de los Andes de Chile y la Universidad Austral de Argentina. El Opus Dei ha logrado que muchos de sus adeptos fueran parte de gobiernos que conformaron las dictaduras cívicos-militares en América Latina, principalmente en el área de educación (Laguado Duca, 2006; Amado, 2014; Rodríguez, 2010 y 2011; Olguín, 2010). Esto se debió a que, a mediados del siglo XX, sus militantes entendieron que muchas reformas educativas eran un avasallamiento de los derechos de los colegios confesionales y vieron con temor el avance del Estado por regular espacios que pensaban como propios. Por un lado, los colegios confesionales sintieron amenazados sus intereses económicos debido al intento de igualar los derechos laborales de los docentes de escuelas privadas y públicas. Por el otro, la autonomía ideológica era vulnerada por el avance del laicismo. Además, les parecía inviable una propuesta de reforma educativa en la que los padres no estuviesen presentes, ya que pensaban que la injerencia del estado en la educación de sus hijos se oponía a los derechos individuales y era parte de una propuesta totalitaria. En Argentina, en 1973 un comunicado de delegados docentes de establecimientos privados cercanos al Opus Dei afirmó que se oponían a una reforma educativa debido a que, según ellos, imponía el laicismo en las escuelas (lo cual lo entendían que era inconstitucional); fomentaba la entrega de niños a guarderías para facilitar la emancipación de la mujer y utilizaba el concepto de propiedad social (según ellos concepto vinculado a ideologías extranjeras). Desde la perspectiva de este movimiento religioso el rol de la familia y de los padres era atropellado como sucedía en los socialismos reales. Como un absurdo puede mencionarse los dichos de Dennis Cardozo Biritos en la Revista Claves (1973). Este miembro del Opus Dei fue uno de los fundadores y rector de la UCA, Universidad Católica Argentina y también fue funcionario del ministerio de educación durante las dictaduras de 1966 y de 1976. En una entrevista en dicha revista afirmó: "[...] se dice que el Estado deberá proveer ropas, zapatos, alimentos y material de estudio a todos los alumnos; ¿significa que las familias que pueden alimentar a sus hijos perderán también ese derecho?” (Cardozo Biritos, 1973).

La crítica más recurrente al progresismo educativo fue la de su afiliación con la ideología marxista. En esa misma entrevista, Cardozo Biritos sostuvo que temían que la reforma educativa abriera las puertas a un lavado de cerebro del marxismo internacional (Cardozo Biritos, 1973). En tanto que la agrupación católica-conservadora mendocina ¡Alerta padres! a la que pertenecía Biritos, publicó en un comunicado en el Diario Los Andes el 18 de septiembre de 1973 que "el marxismo internacional pretende imponer sus aberrantes principios materialistas y apátridas en la educación de nuestros hijos".

En cuanto a la segunda estrategia, Estados Unidos consideró a la Teología de la Liberación como una amenaza a sus intereses en América Latina y vio con beneplácito la persecución contra sus promotores realizada por Juan Pablo II y el cardenal Ratzinger (García, 2014, p.91). Una de las estrategias fue el nombramiento de obispos conservadores en regiones donde la teología de la liberación tenía gran número de adeptos. El Opus Dei consiguió 25 obispos y dos cardenales (uno de ellos peruano) ya que su orientación, conservadora en lo moral y capitalista en lo económico, le fue de gran utilidad a la visión de la Iglesia que proponía Juan 
Pablo II (Steinleen, 2011). En Latinoamérica pueden mencionarse a los nombramientos de Antonio Arregui Yarza (arzobispo de Guayaquil, Ecuador); Alfonso Delgado Evers (arzobispo de San Juan, Argentina); Luis Gleisner Wobbe (obispo auxiliar de La Serena, Chile); Juan Ignacio González Errázuriz (obispo de San Bernardo, Chile); Francisco de Guruceaga Iturriza (obispo de La Guajira, Venezuela); Juan Ignacio Larrea Holguín (arzobispo emérito de Guayaquil); Rogelio Ricardo Livieres Plano (obispo de Ciudad del Este, Paraguay); Rafael Llano Cifuentes (obispo de Nova Friburgo, Brasil); Ignacio María de Orbegozo y Goicoechea (obispo de Chiclayo, Perú); Francisco Polti Santillán (obispo de Santiago del Estero, Argentina); Hugo Eugenio Puccini Banfi (obispo de Santa Marta, Colombia); Adolfo Rodríguez Vidal (Obispo de Los Angeles, Chile); Fernando Sáenz Lacalle (arzobispo de San salvador); Luis Sánchez-Moreno Lira (Arzobispo de Cuzco, Perú) y Juan Antonio Ugarte Pérez (Arzobispo de Arequipa, Perú) ${ }^{9}$ (Cejas, S/F). A este grupo se debe agregar a Juan Luis Cipriani Thorne, arzobispo de Lima y primer Cardenal del Opus Dei. Sus declaraciones conservadoras, su apoyo al gobierno de Fujimori y el enfrentamiento con las organizaciones de defensa de los Derechos Humanos y con el ala más progresista de la iglesia católica peruana, han generado numerosas críticas (Vargas Llosa, 2002).

Otro caso que también generó gran desconcierto fue el nombramiento del arzobispo de San Salvador, Monseñor Sáenz Lacalle, sucesor de Monseñor Oscar Arnulfo Romero, asesinado por militares, mientras que el nuevo obispo, además de pertenecer al Opus Dei, era el capellán de las Fuerzas Armadas salvadoreñas (Normand, 2001). Ya en el cargo Sáenz Lacalle hostigó al sector de la iglesia que había sido afín a Romero (Gaymer, 2005) y se transformó en un gran apoyo para los grupos conservadores de ese país (Ruiz, 2005).

Conclusiones: la funcionalidad del conservadurismo cristiano a los intereses de Estados Unidos en la Guerra Fría

Como hemos observado en este artículo varios de acciones de los grupos conservadores eran afines a desmovilizar a sectores que eran contrarios a los intereses de Estados Unidos en la región. Esto los hizo, de modo consciente o fortuito, aliados en sus objetivos.

En primer lugar, se puede afirmar que, por un lado, el pietismo del protestantismo conservador favoreció la exacerbación del individualismo, el rechazo a la práctica política y la reducción de la religión a la esfera privada. Como afirmábamos al inicio, esta característica del conservadorismo protestante ha sido, con razón, la más señalada. Como ejemplo podemos mencionar la caracterización de las comunidades evangélicas chilenas durante la dictadura cívico-militar de A. Pinochet como mayormente apolíticas y concentradas en la vida espiritual de Evguenia Fediakova (2010, p.100). Sin embargo, a pesar que esto fue cierto en gran parte del transcurso de la Guerra Fría, tampoco se debe olvidar la gran proliferación de partidos conservadores confesionales que surgieron en al menos doce países latinoamericanos desde fines de los ochenta.

En segundo lugar, hemos visto que tanto los protestantes conservadores, como los católicos integristas y neointegristas, proponían un discurso que demonizaba a los socialismos reales y clausuraba cualquier reivindicación de intervención estatal o de defensa de derechos acusándola de marxista y, por ende, de atea. Esto impidió el debate sobre algunas políticas

${ }^{9}$ Sólo se menciona entre paréntesis el último nombramiento que obtuvo el sacerdote en Latinoamérica. Aunque en algunos casos fueron obispos en más de una diócesis u obtuvieron otros cargos en Roma. 
progresistas o de modernización de las sociedades, llevando las discusiones a un lugar irracional en el que se le quitaba el apoyo a cualquier propuesta innovadora por el temor a que decantara en un ateísmo.

En tercer lugar, los cristianos conservadores más lejanos al pietismo conformaron un activismo político-religioso que dio origen a la participación de grupos identificados religiosamente, en una serie de actividades propuestas para influir en los debates, las políticas públicas y las legislaciones (Vaggione, 2009). Esta influencia política de las religiones tuvo como objetivo principal conservar un orden social que se consideraban amenazado, es decir que en gran medida era un activismo reactivo a los cambios culturales y legales que afrontaron las sociedades latinoamericanas durante el siglo veinte. En los apartados anteriores se describió una multiplicidad de prácticas que llevaron a cabo sectores cristianos conservadores, que fueron afines con los objetivos de la Casa Blanca para América Latina. En este sentido podemos ver una serie de estrategias que van desde el abstencionismo político y la militancia intraeclesial a otras que procuraron el control de políticas públicas, estas últimas son las cuatro últimas filas del siguiente cuadro:

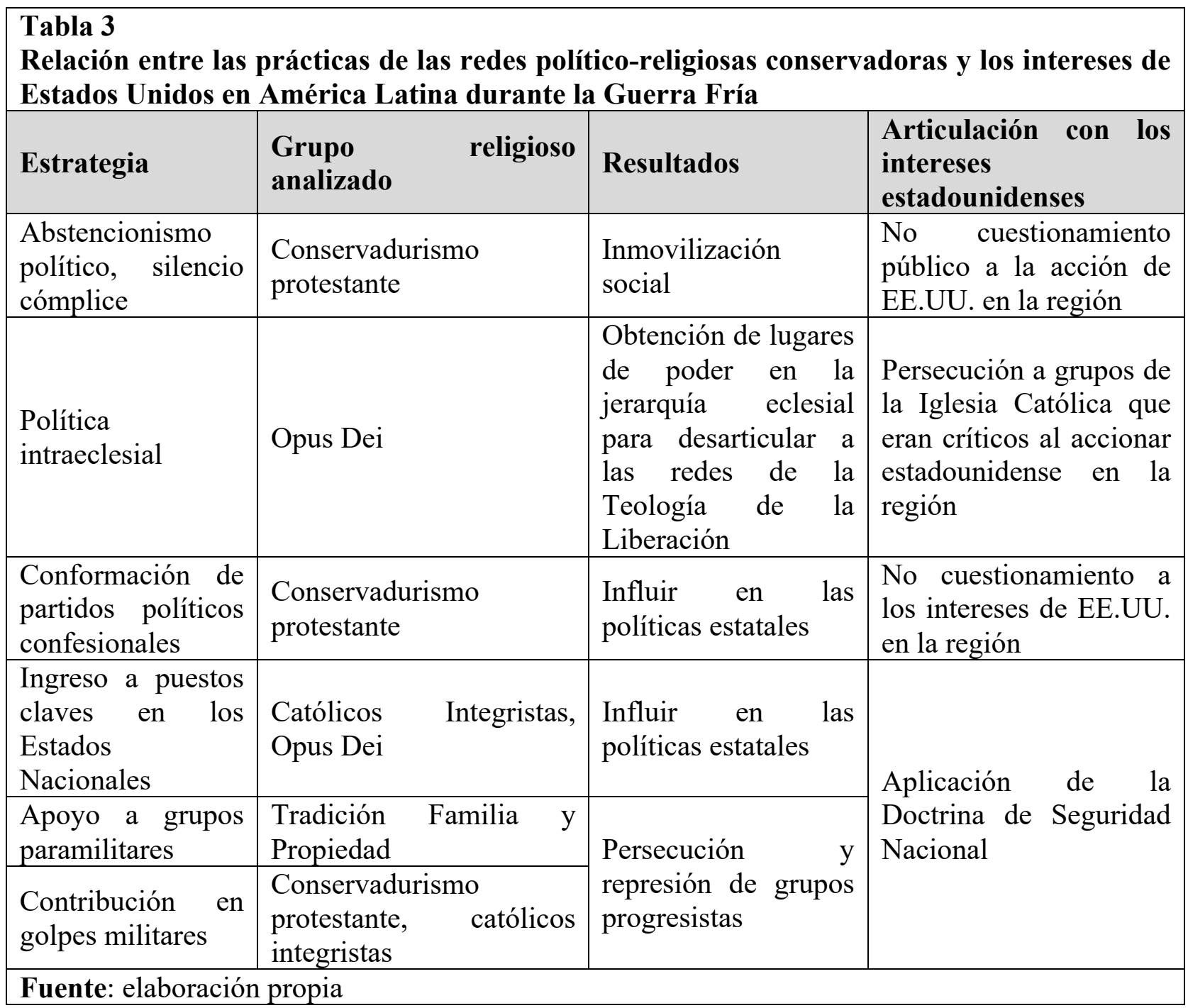


También debe señalarse que estas estrategias no han estado exentas de violencias discursivas, institucionales (en el caso de la política de persecución intraeclesial, por ejemplo) y hasta de represión estatal y paramilitar. Todo esto rompió lazos, generó desconfianzas y fomentó un clima de individualismo que permitió la ofensiva neoliberal de los años posteriores, en el marco de la cual se conformarán los partidos políticos confesionales conservadores evangélicos.

\section{Referencias Bibliográficas}

Acevedo, J. (2016). Entender la sociedad y la política latinoamericanas en clave narrativa. Una entrevista a Omar Rincón. Conexión, (6), 87-99.

Amado, F. (2014). El peso de la cruz: Opus Dei en Uruguay. Montevideo: Sudamericana.

Amat y León, O. (2015). El funcionamiento, fortalecimiento y estrategias de los grupos opositores de los derechos. Presentación en la 3ra Conferencia Subregional Andina. Lima, 5 de noviembre de 2015

Barón, G. (2015). Matriz ideológico-política cristiana e izquierda social: La crítica a la modernidad en la revista Alternativa Latinoamericana (1985-1990). Religião e Sociedade, 35(2, 249-273

Bastian, J. (1999) Los nuevos partidos políticos confesionales evangélicos y su relación con el Estado en América Latina. Estudios sociológicos, XVII (49), 153-173.

Berger, P. y Luckmann, T. (1995) Modernidad, pluralismo y crisis de sentido. La orientación del hombre moderno. Barcelona: Paidós.

Boyer-Araujo, V. (1993). Les traditions risquent-elles d'être contaminées ? Paradigmes scientifiques et orthodoxie religieuse dans les cultes de possession au Brésil. Journal de la Société des Américanistes, 79, 67-90.

Bourdieu, P. (1993). Espíritus de Estado y genésis y estructura del campo burocrático, Actes de la Recherche en Sciences Sociales, 96/97, 49-62

Bustelo, G. (2001) Impacto de la dictadura pinochetista en Mendoza. 1973-1988, Revista de Estudios Trasandinos, 5, 352-372

Cardozo Biritos, D. (1973), La naturaleza humana es débil e inclinada al mal, Claves, Mendoza, octubre 5 de 1973.

Caro, I. y Fediakova, E. (2000). Los fundamentalismos religiosos: etapas y contextos de surgimiento. Fermentum. Revista venezolana de sociología y antropología, 10(29), 453467.

Castells, M. (1997) La era de la información. Economía, sociedad y cultura. 1. La sociedad red, Madrid: Alianza.

Chacón, J. (2015) La mano de Dios, la voz del General: introducción a la lectura de la economía política de la carne de Efraín Ríos Montt. Vida Pensamiento, 35 (1), 79-112

Chávez Hartley, L. (2011). El perfil de un Batallador católico. Centenario de Plinio Correa de Oliveira. La Razón Histórica, (16), 86-88.

Cifuentes, M. (2007). Pluralismo en el catolicismo actual. Creer y poder hoy, 363-373 
Claves (1973) El caso Thieme-Sessa. La farsa de dos chilenos, Claves, 18/05/1973, 43

Comisión de Estudios de las TFPs (1990) 1967/1974 De Frei a Allende. La TFP chilena y sus cohermanas ante el crepúsculo artificial de Chile. Tradición, Familia, Propiedad. un ideal, un lema, una gesta. Recuperado de www.pliniocorreadeoliveira.info/GestaES_0403_19671974.htm

Concatti, R. (2009) Hubo cristianos entre los torturadores (entrevista a Rolando Concatti, uno de los 27 sacerdotes expulsados en 1965), MDZ, 25/12/2009

Córdova Villazón, J. (2014). Viejas y nuevas derechas religiosas en América Latina: los evangélicos como factor político. Nueva sociedad, (254), 112-123.

Cucchetti, H. (2007) De la resistencia peronista al comunitarismo católico: un linaje de conversión católica en trayectorias justicialistas. Nuevo Mundo Mundos Nuevos. Recuperado de http://nuevomundo.revues.org/3847

Daniel, F. Derrois, R. y de Ávila, C. (2006) A política da encruzilhada: considerações sobre a política interna das religiões afro-brasileiras no processo eleitoral riograndense. Debates do NER, 7(10), 39-50.

De Mattei, R. (1998). El cruzado del siglo XX: Plinio Corrêa de Oliveira. Madrid: Encuentro. Duhalde, E. (1983) El Estado Terrorista argentino, Buenos Aires: El Caballito

El Siglo (7/5/73) Thieme encabezaba un comando destinado a la guerra civil, El Siglo, 3

El siglo (8/5/73) Misión de Thieme: Organizar el plan conspirativo contra Chile, El Siglo, 9

El siglo (9/5/73) Querían desencadenar guerra civil antes del 21 de mayo, El siglo, 3

Federación Internacional de Derechos Humanos (2013). Genocidio en Guatemala: Ríos Montt Culpable, Informe julio 2013, 613e, París: FIDH

Fediakova, E. (2010). Tradición religiosa y juventud evangélica chilena-1990-2008: ¿Choque de generaciones? Estudos Ibero-Americanos, 36(1), 87-117.

Fiducia (1974) 1970-1973. Lo que la TFP hizo por Chile, Fiducia, XII, 36, 56.

Figueroa Ibarra, C. (1990). Guatemala: el recurso del miedo. Nueva Sociedad, 105, 108-117.

Flores, C. (2017). ¡El caso por genocidio de Ríos Montt y la elaboración cultural del terror entre los q'eqchi'de Guatemala! Investigaciones Sociales, 20 (36), 261-274.

García, J. (2014). La influencia de la geopolítica estadounidense en la Teología de la Liberación latinoamericana en el periodo 1960-1990. Geopolítica (s). Revista de estudios sobre espacio y poder, 5(1), 79-98.

Gaymer Mogro-Moreno, M. (2005). La función ideológica del Opus Dei: la legitimación de un orden social estratificado. Tesis de Lic. en Sociología, Univ. Alberto Hurtado, Chile

Gold, D.; Lo, C, y Wright, E. (1985) Recientes desarrollos en la teoría marxista del Estado Capitalista. En Offe, Claus y otros Capitalismo y Estado, Madrid: Revolución.

Gomes, G. (2016). Héroes y demonios. Los jóvenes del Frente Nacionalista Patria y Libertad en el Chile de la Unidad Popular (1970-1973). Revista de la Red Intercátedras de Historia de América Latina Contemporánea, año 2, (4), 57-73

Gongalves de Freitas, M. y Montero, M, (2006) Las redes comunitarias. En M. Montero, Teoría y práctica de la psicología comunitaria: la tensión entre comunidad y sociedad. Buenos Aires: Paidós.

Kornis, M. (2009) Liga Eleitoral Católica (LEC), Centro de Pesquisa e Documentação de História Contemporânea do Brasil. Recuperado de http://www.fgv.br/cpdoc/acervo/dicionarios/verbete-tematico/liga-eleitoral-catolica-lec

Kretzschmar, L. (1989) Pietism, Politics and Mission: An examination of the views and activities of South African Baptists. Missionalia, 17 (2), 103-114. 
Laclau, E. (1985) Teorías Marxistas del Estado: debates y perspectivas. En: N. Lechner. Estado y Política en América Latina, México: SXXI.

Laguado Duca, A. (2006). General Onganía and the Military Nationalism in Argentina. Universitas humanística, 62, 239-260.

Lopez Espinola, N. (2016). La incidencia política de la iglesia católica en Paraguay: durante el Gobierno de Fernando Lugo (tesis de licenciatura en Ciencia Política y Sociología). Foz do Iguaçu: UNILA.

Makaran-Kubis, G. (2009) El nacionalismo étnico en los andes, el caso de los aymaras bolivianos, Latinoamérica, 49, 35-78

Mallimaci, F. (1992). El catolicismo argentino desde el liberalismo integral a la hegemonía militar. En Mallimaci, F. 500 años de cristianismo en Argentina, Buenos Aires: CEHILA, 197-365.

Mallimaci, F. y Giménez Béliveau, V. (2007), Creencias e increencia en el cono sur de América Latina. Entre la religiosidad difusa, la pluralidad del campo religioso y las relaciones con lo público y lo político, Revista Argentina de Sociología, 5 (9), 44-63

Mallimaci, F., Donatello, L. y Cucchetti, H. (2006) Religión y política, Estudios Sociológicos XXIV (71), 423-449.

Mansilla, M. y Orellana, L. (2015). Participaciones activas y pasivas de los evangélicos en los espacios públicos y políticos en Chile entre 1973 y 1999. Revista de Estudios Sociales, (51), 146-159.

Mena Cabezase, I. y Flores Mejía, L. (2007) Un movimiento étnico-religioso en el área de Copán (Honduras): La iglesia milenarista del siglo nuevo, Revista de Antropología Iberoamericana, 2 (1), 19-42.

Normand, F. (2001) El poder del Opus Dei, Le Monde Diplomatique. Santiago de Chile: Editorial Aun Creemos en los Sueños.

Olguín, F. (2010). La formación de una nueva mentalidad religiosa de la elite empresarial durante la dictadura militar, 1974-1990. El catolicismo empresarial del Opus Dei. Cultura y Religión, 4(1), 105-124.

Orellana, P. (1981) El exilio chileno, Falmer: Inst. of Development Studies-University of Sussex.

Pacheco Rivas, A. (2012) Estructuración y cambio social en sociedades indígenas de Latinoamérica. El caso de la relación entre la sociedad mapuche y el Estado de Chile. Desacatos, 38, 157-168.

Paredes, A. (2004). La Operación Cóndor y la guerra fría. Universum, 19(1), 122-137.

Parker Gumucio, C. (2006) Religión y el despertar de los pueblos indígenas en América latina. Alteridades, 16 (32), 81-90.

Pereira Ramalho, J. (1988) Construir a esperança. Encontro Latino-americano e caribeño de Organismos Ecumênicos "Mauricio López”, São Paulo: CLAI.

Piedra, A. (1999). La derecha político-religiosa de Guatemala. Ibero-amerikanisches Archiv, 25 $(1 / 2), 175-189$.

Porras, J. (2003) De Internet, la sociedad red y la política. La emergencia de la gobernabilidad digital, Polis, 1 (4). Recuperado de http://www.redalyc.org/articulo.oa?id=30500413

Quevedo, L. (1999) Política, medios y cultura en la argentina de fin de siglo. En D. Filmus (comp.), Los noventa. Política, sociedad y cultura en América Latina y Argentina de fin de siglo, Buenos Aires: Eudeba, 201-225.

Restrepo, A. (1982) Capas Rojas y León Rampante. Bajo la inspiración de la Virgen de Fátima... y de Mussolini, Nación (Bogotá), 19/07/1982. 


\section{Alejandro Paredes}

Rodríguez Agüero, L. (2009) Mujeres en situación de prostitución como blanco del accionar represivo: el caso del Comando Moralizador Pío XII. Mendoza 1974-1976. En Andujar, Andrea y otras de minifaldas, militancias y revoluciones. Exploraciones sobre los '70 en América Latina, Buenos Aires: Luxemburg.

Rodríguez, L. (2010) Iglesia y educación durante la última dictadura en Argentina, Revista Cultura y Religión, IV (2), 4-19 . (2011). La influencia católica de la educación. El caso del ministro Juan Rafael Llerena Amadeo (1978-1981). Estudios, 25, 141-157.

Ruderer, S. (2012) Cruzada contra el comunismo. Tradición, Familia y Propiedad (TFP) en Chile y Argentina. Sociedad y religión, 22 (38), 79-108.

Ruiz, E. (2005) Cruces y sombras: perfiles del conservadurismo en América Latina. Lima: Promsex.

Steinleen, C. (2011). La ética neointegrista del Opus Dei. Si Somos Americanos, Revista de Estudios Transfronterizos, 11(2), 143-155.

Stoll, D. (1990). ¿América Latina se vuelve protestante?: las políticas del crecimiento evangélico. Quito: Abya-Yala. . (1993). Between two armies in the Ixil towns of Guatemala. Nueva York: Columbia University Press.

Tamayo Acosta, J. (2005) Juan Pablo II y el Opus Dei. Socios, Madrid, 31 de mayo de 2005. TFP (1973) La autodemolición de la iglesia, factor de demolición de Chile, Tradición, Familia y Propiedad, 18, diciembre de 1973.

Vaggione, J, (compilador) (2009). El activismo religioso conservador en Latinoamérica. Córdoba (Arg.): CEA, CONICET, UNC.

Vallverdú, J, (2005) Violencia religiosa y conflicto político en Chiapas, México. Nueva Antropología, XX (65), 55-74

Vargas Llosa, M, (2002) Cobardía e hipocresía, El País, 8/12/2002.

Villegas, A. (2017). Reinado social de Cristo y laicización estatal: la percepción de las relaciones Iglesia-Estado en el discurso lefebvrista. Letras Históricas, 16. 193-224

Weber, M, (1998) La ética protestante y el espíritu del capitalismo. Madrid: Itsmo. 